\title{
Mental health and the news media in Aotearoa New Zealand: Key informant perspectives
}

\author{
Natasha Oliver, Liz Beddoe and Carole Adamson, University of Auckland
}

\begin{abstract}
INTRODUCTION: Without personal experience or specific background knowledge of an issue, individuals exposed to news media are limited in their ability to gauge the accuracy of media content. The perception of people with mental illness as dangerous or incompetent allows for discrimination to occur, often resulting from inaccurate portrayals in the media.
\end{abstract}

METHOD: A small, qualitative study was undertaken to explore key informant perspectives on the representation of mental health issues in the current Aotearoa New Zealand media context. Eight semi-structured interviews were carried out with key informants; each participant provided at least one of the following perspectives: mental health professional, mental health advocate, mental health consumer and/or media personnel.

FINDINGS: The participants in this research found that news media strongly influence how the public views mental health, but believe media representation has improved in recent years. However, participants described an absence of stories illustrating successful interventions and felt that the portrayal of mental illnesses are still misrepresented and stigmatised by the media. Mental health services and mental health professionals were seen as poorly represented by the news media, which was thought to deter help-seeking and hinder trust.

CONCLUSION: Public attitudes towards mental health have a significant impact on the lives of those experiencing mental distress. The news media have the ability to change public perceptions; however, this influence can be either harmful or helpful. Mental health stories need to be consistently contextualised and use inclusive language in order to a make a positive largescale change in public attitudes.

KEYWORDS: Mental health; mental illness; news media; service-user perspective

AOTEAROA NEW ZEALAND SOCIAL WORK 32(4), 158-171.

CORRESPONDENCE TO: Liz Beddoe

e.beddoe@auckland.ac.nz
Mental health is a significant concern in Aotearoa New Zealand, with approximately one in six New Zealanders being diagnosed with a mental health condition at some point in their lives (Mental Health Foundation of New Zealand (MHF), 2014). A perception of people with mental illness as dangerous and unpredictable has allowed for discrimination and the social distancing of those living with a mental illness. Charles and Bentley (2016) argued that this discrimination is a result of exaggerated, distorted, and often incorrect news media portrayals of people with mental illnesses. For people without experience of mental illness, either in their personal or professional lives, the news media provide the major source of knowledge and can have a significant impact on an individual's understanding and response to mental illness. 
Misunderstanding and fear of mental illness have led to people being excluded from their community and often make it difficult for people to find housing or employment and be involved in social activities (Drake \& Whitley, 2014). This can have a significant impact on self-esteem and quality of life for many New Zealanders. Alternatively, people experiencing mental distress may try to hide their experience due to fear or shame, which can cause additional stress and often inhibits help-seeking behaviours. Research by Niederkrotenthaler et al. (2010) suggests that shame about mental distress may be related to high rates of suicide and it is therefore important to understand how mental illness is currently portrayed in the Aotearoa New Zealand news media to ensure accurate information and inclusive messages are being conveyed to the public. Guidelines to support journalists are available and the Mental Health Foundation of New Zealand media guidelines provide an example of how they can be resourced (MHF, 2018).

The research project reported in this article involved participant interviews and a content analysis of news media in printed or online formats. The content analysis is reported elsewhere (Oliver, 2019). The following literature review addresses the concept of stigma and news media influence on public perceptions of mental illness, including self-perception for those living with a mental illness, while understanding that the general public will have available to them a far wider portrayal of mental health.

\section{Literature}

Public attitudes towards mental illness are influenced by, and themselves influence, news media coverage (Rhydderch et al., 2016). Mental health topics appear in various forms of media, including children's programmes, adult fiction, social media and news content. The focus of this article is representation in news media, although other forms together help to inform and influence the general public's ideas on mental health. International research suggests, for example, that it is the interplay between entertainment media and the reporting of news which allows for stigmatising images of mental illness to be maintained and amplified (Hall, 2001; Stuart, 2006). It was beyond the scope of this study to explore the influence of other media in detail.

Stigma is a significant dimension of wellbeing and identity for people with mental illness and it therefore is of concern how they are represented in the media. Stigma can be perceived as part of personal identity and Scambler notes that when stigma is "internalised by putative possessors of stigma the consequence is 'self-stigma'" (Scambler, 2009, pp. 446). Steward et al. (2008) suggested that people's internalised self-concept becomes aligned with the stigmatising responses of, and use of labels by, others. Participants in Peterson, Barnes, and Duncan's (2008) Aotearoa New Zealand research on self-stigma highlighted the news media's role in perpetuating sensationalised stereotypes of mental illness. Service-user-led movements such as Mad Pride (Schrader, Jones, \& Shattell, 2013), the Nutters' Club in Aotearoa New Zealand (https: / / thenuttersclub.co.nz/) and the development of academic Mad Studies (Beresford, 2019), have reclaimed pejorative labels as an act of resistance and an assertion of positive identity. Nevertheless, a primary focus of many mental health advocacy campaigns and organisations such as the Mental Health Foundation's Like Minds campaign (Ministry of Health and Health Promotion Agency, 2014) is the reduction of stigma (including self-stigma) through reducing othering in processes such as labelling in popular language. Here, we make a distinction between reclamation of pejorative words by insider / service-user groups (e.g., the Nutters' Club) and the persistence in othering by the use of labels. Aragonès, López-Muntaner, Ceruelo, and Basora (2014) noted that, like other groups subject to stigma and discrimination (e.g., because of race, disability or sexuality), changing the use of language in the media is an important step towards changing 
attitudes. Wahl, Wood, and Richards (2002) make the distinction between language which speaks of people with disorders and language which equates people with their diagnostic label, such as labelling people as "schizophrenics," or "borderlines." Aragonès et al. (2014) argued that this language perpetrates stigma as it suggests that people are defined by their illness and this detracts from their other roles and identities. The results of Wahl et al.'s (2002) research showed an equal likelihood of both types of language occurring in the media when talking about mental illness, with no significant reduction in references to people as their disorders during their 10-year study period. More recent studies suggest a shift towards more positive representation of mental health in media language (Kenez, O'Halloran, \& Liamputtong, 2015; Thornicroft et al., 2013), with research suggesting that mass media and social media campaigns have made significant contributions to changing public discourses (Sampogna et al., 2017).

Mental health campaigns have increased the public's awareness and understanding of certain disorders, improving public attitudes, which is subsequently reflected in the media (Aragonès et al., 2014; Clement et al., 2013; Sampogna et al., 2017; Vaughan \& Hansen, 2004). The only Aotearoa New Zealand studies looking into the media representation of mental health were published more than 10 years ago (e.g., Nairn, Coverdale, \& Claasen, 2001; Nairn, 2007; Wilson, Nairn, Coverdale, \& Panapa, 1999). While the findings of these studies do provide some indication of Aotearoa New Zealand's attitudes towards mental illness, they do not take into account the impact of recent campaigns seeking to destigmatise mental illness, such as "Like Minds Like Mine" (Ministry of Health and Health Promotion Agency, 2014). Arguably, this campaign (established in 1997 with the aim of reducing stigma and discrimination and increasing social inclusion for those with experience of mental illness) has had a significant impact. The majority of participants in Thornicroft,
Wyllie, Thornicroft, and Mehta's (2014) study reported an improvement in public attitudes over the last five years, which they attributed to the Like Minds campaign. However, much of the improvement in attitudes is related to more common experiences of mental distress, such as depression and anxiety, with specific diagnoses, such as schizophrenia, still being misrepresented in media reports (Kenez et al., 2015; Neto, Figueiras, Campos, \& Tavares, 2017; Rhydderch et al., 2016). The research reported in this article took a snapshot of key informant perspectives on current news media presentations of mental illness.

\section{Method}

Data for this article were obtained as part of a Master of Social Work research project (Oliver, 2019). The study was approved by The University of Auckland Human Participants Ethics Committee number 021531. A content analysis of news media articles on depression and suicide during the period January 24, 2017-January 23, 2018 and findings of that part of the study will be reported separately.

The research question "How is mental health portrayed in Aotearoa New Zealand mass media?" was used to guide this project. There were two research objectives:

1. To gain an understanding of key informant perspectives on the current media representation of mental health;

2. To gain an understanding of key informant perspectives on how the media portrayal of mental health might impact on different stakeholders.

\section{Participants}

The first author carried out eight semistructured interviews with key informants who were invited to participate based on their knowledge and experience of mental 
health. Participants were categorised into one of four categories: media personnel, consumer perspective, mental health advocate or mental health professional. This research used purposive sampling to allow the taking of research questions into consideration when making sampling decisions (Bryman, 2012). All participants were living and working in Aotearoa New Zealand. Auckland participants were interviewed face to face and interviews with those based outside Auckland were conducted using Skype or over the phone.

\section{Semi-structured interviews procedure}

Semi-structured interviews were used to collect data. This form of interview was chosen in order to ensure thorough exploration of the topic with all participants while allowing for flexibility in the phrasing and order of questions. Open questions were used to encourage participants to provide detailed answers and to describe their own understanding of the current media representation of mental health. Additionally, the semi-structured interview format allowed for responses to develop organically and enabled the asking of questions not included in the question guide when an interesting or unanticipated theme emerged. Interviews took between 30 and 90 minutes as participants varied significantly in how much they wanted to say. Each of the interviews, although of different lengths, were appropriate for the individual participant and the time taken allowed for sufficient exploration of the topic (Gill, Stewart, Treasure, \& Chadwick, 2008).

The researcher paid careful attention to keeping questions neutral and to encouraging participants to consider all facets of the media's representation of mental health, rather than presume a negative impact. This avoided limiting participant's answers or causing prejudice towards a particular position. A final open question ensured that all participants had the opportunity to voice their thoughts and were not limited by the questions asked.

\section{Qualitative analysis}

Transcription began alongside interviewing which allowed reflection on the interview process and the identification of themes to help inform subsequent interviews in line with the principles of grounded theory (Gubrium, Holstein, Marvasti, \& McKin, 2012). During analysis, the first author listened to the interview recordings again to help contextualise statements and deepen understanding of the participant perspectives. Open coding was used during the initial analysis to identify, name, and describe the concepts within the text. This process involves reading and dissecting every part of the text in order to understand the meaning (Borgatti, 2014).

The next stage of coding involved combining related nodes and making connections between codes. This axial coding aims to find causal explanations for events and interactions (Marshall \& Rossman, 2014). One of the main criticisms of coding in qualitative data analysis is the risk of losing the context of what has been said (Bryman, 2012). This risk was reduced by returning to recordings while undertaking axial coding allowing interpretation of meaning in the context of comments and the tone and intonation in my interpretation of their intended meaning.

Finally, the selective coding procedure involved revisiting the data and the codes and narrowing the focus to the most significant categories. In this process data were chosen which best illustrated the prominent themes.

\section{Ethics}

A written, informed consent form, requesting participants' signature prior to being interviewed, was provided. Participants were given printed information about the purpose of the research, and measures taken for confidentiality; however, they were made aware that while confidentiality was observed, complete anonymity could not be 
guaranteed due to the small and connected communities from which they were drawn. Participants were offered relevant contacts for support if they experienced any distress arising from topics discussed during the interview.

\section{Findings}

This research project explored the perspectives of media personnel, mental health advocates, mental health professionals and mental health consumers on the media's representation of mental health. All participants had had some involvement in an area of mental health during their working lives and both of those in the media personnel category have been publicly recognised for their contribution to mental health journalism. Six key themes were developed in the analysis: news reporting, language, context, mental health services, negative messages and positive messages. Participants' quotes in the text have been used to illustrate the findings.

\section{News reporting}

Opportunities for service-users and members of the public to positively influence the news media were identified by participants. In particular, participants felt that the quality and sensitivity of mental health stories could be improved by mental health service providers and service-users providing feedback and liaising with the media. In addition, increased training for journalists was frequently requested by participants in order for mental health stories to be hopeful and reflective of real-life struggles with mental illness.

I think there ha[ve] been rapid improvements in the news media, just in terms of things like providing helplines and other resources for readers at the bottom of stories and consulting a bit more with kind of people in the sector and people who have experienced mental distress, just giving them a bit more of an input so that [journalists] understand the repercussion[s], or the potential repercussions of what they're writing. (Media Personnel 2)

Participants acknowledged the difficulties for journalists in accurately reporting on mental health issues. In particular, two barriers were discussed. The first of these, acknowledged by mental health advocates and professionals was liaison, which is, in part, driven by service-users' fear of being misrepresented or discriminated against, as well policies or restrictions for service providers in speaking to the media. The second involved the newsroom pressures, including time restraints and expectations for stories to be succinct, lucrative and attention grabbing.

\section{Language}

The second identified theme concerned the language used in mental health stories. Participants spoke about the importance of using inclusive language when reporting on mental health and highlighted the negative connotations attached to some commonly used words and terms. While there was an agreement that the language used has improved over recent years, participants acknowledged the tendency for the media to use mental illness or a diagnostic label to reduce a person to a single component of their life. It was argued that a fundamental change in the language used by media is necessary in order for the public to recognise people as more than "a mental health patient."

Another issue that was brought up in the language area was discussion around suicide. Several participants described the careful wording of the media in the reporting of suicide to say as much as they can within legal restrictions.

Sometimes it almost feels a bit gratuitous when they might talk about a suicide story, and they know they can't mention the method, but they mention enough about the case for you to know the method. (Mental Health Advocate 1) 
Mental health advocates and consumers felt this practice was harmful as it was seen to encourage a hopeless orientation for individuals struggling with suicidal ideation.

\section{Context}

The context of people's lives was identified as significant in both the development of mental distress and in one's ability to recover.

If you think about mental health in the broader sense, people's mental health is affected by things like poverty, homelessness, expensive homes in Auckland, cultural disconnection, social isolation ... those kinds of macro level things. (Mental Health Professional 1)

Several participants acknowledged the importance of including context in balanced reporting of mental health stories and speculated that the lack of context fosters social distance and makes it easy to for the public to place blame on individuals. Vague news stories of violence also play into this by encouraging the public to make assumptions about a person's mental health and motives for aggressive behaviours. Participants felt that mental illness was recognised as correlated with stressful life events and is particularly common among individuals with experiences of trauma. Many participants argued that, with context, experiences of mental distress become more understandable and relatable, and this decreases news value as stories lose the ability to elicit shock and fear in the audience.

\section{Mental health services}

Another recurring theme in the interviews concerned the difficulties experienced within the mental health system arising out of staff and resource shortages. The increased demand for mental health services has led to long waiting lists, high thresholds, an acute intervention focus, and many services are at full capacity. There was recognition that negative media coverage of services may further discourage people from working in the mental health sector due to the current challenges. Furthermore, a number of participants linked the negative media representation of mental health services to increasingly risk-averse work environments. Participants described mental health professionals as fearful of being "named and shamed" by the media and, as a result, treatment is more likely to become overly medicalised and coercive, and services become more private and less likely to innovate.

Interestingly, participants described two paradoxical media representations of mental health professionals. The first being these professionals as people who frequently lose patients from mental health facilities, lock people up and force them to take medication. The other, insinuating that mental health professionals have all the answers and can offer quick-fix solutions to cure mental illness. Both of these media representations were seen as harmful as they can deter help-seeking or create unrealistic expectations.

The purely medicalised representation of mental health services was another issue raised in the interviews. Participants felt that, based on media representations, the public would lack an awareness of what mental health support services are available and would have a distorted understanding of how services operate. The other difficulty here is that the media focuses predominately on the failings of the mental health services and does not give enough attention to the successes occurring. One of the consequences of this is that it discourages help-seeking, as people are dubious about the help mental health services can provide. Several participants explained that, when someone approaches the media about mental health services, it is usually because they are angry or upset and therefore these are the loudest voices heard. Participants explained that stories showing mental health services in a positive light would provide balance to the 
narrative and open up discussions about effective interventions.

\section{Negative messages}

In looking at the negative messages in the media's dialogue on mental illness, an association with violence and an othering discourse were two of the strongest themes. Mental health professionals and advocates spoke of news media highlighting mental illness as a characteristic of difference and using it to separate and discriminate. For example, stories linked exaggerated, inaccurate or decontextualised accounts of violent events to mental illness, reflecting similar research (Murphy, Fatoye, \& Wibberley, 2013; Nairn, 2007). Some participants claimed that, when a violent incident occurs, the media tend to speculate that the person responsible acted as a result of a pre-existing mental illness. This may cause the public to link mental illness to violence and learn to think of the two as intrinsically connected; however, research evidence such as that of Simpson, Mckenna, Moskowitz, Skipworth, and Barry-Walsh (2004) suggests that people living with mental illness are more likely to be victims of violence rather than its perpetrators.

These links enable othering, and examples were provided where people have avoided someone with a mental illness, staying away from where they live, or crossing the street to avoid walking past them. In addition to the othering discourse, fear of mental illness can prevent social inclusion and acceptance of those experiencing mental distress.

Self-stigma was another theme raised by both mental health professionals and advocates, echoing Scambler (2009). This was described as including feelings of shame associated with mental illness, guilt for burdening others and feeling weak and embarrassed about having difficulty coping independently. These participants felt that self-stigma was a barrier to recovery and can drive suicidal thoughts. Negative media coverage was linked to self-stigma as it feeds self-doubt and discourages participation in normal activities.

And that has enormous knock-on effects with our suicide statistics. Enormous knock-on effects with our economy. So, people are unable to get jobs that they want, need, value. They're unable to enter further education and training. Either through their own self-stigma or being rejected from some of those training courses. (Mental Health Advocate 1)

\section{Positive messages}

The final theme which came out of the interviews concerned positive messages in the media. Participants were united in their belief that positive media representations have a normalising effect and agreed that anti-stigma campaigns are having a positive impact on the way the public views distress. Several participants commended the work of public figures for speaking out and engaging with the media to share their personal stories, asserting that these are the most valuable as they humanise mental distress.

So, more people see stories of people like them in the media, they're more likely to go, "oh, what I'm going through happens to other people as well, it's kind of normal, I can get help for this, I can reach out, I don't need to be so embarrassed or shameful about experiencing these things." I think that's the greatest positive. (Mental Health Advocate 1)

Depression and anxiety were discussed by several participants as being recognised in the media as normal experiences. However, participants felt that the same had not occurred for some episodes of mental distress such as psychosis. This is consistent with existing literature, for example, the research done by Neto et al. (2017) and Rhydderch et al. (2016), and suggests the perpetuation of stigma against those experiencing mental illnesses that are associated with risk, predominantly psychoses, and especially those associated 
with violence towards others (Berry \& Whitley, 2016; Simpson et al., 2004). The importance of talking about mental health issues, including suicide, was emphasised during interviews. Participants felt that respectful media discourse helps to demystify mental illness and can educate the public, so illness becomes less of the "unknown other." Participants highlighted other benefits of a normalising discourse, including reducing feelings of shame and isolation, increasing feelings of acceptance, preventing suicide and supporting recovery.

In line with recent research (Rhydderch et al., 2016; Whitley \& Wang, 2017), many participants described an improvement in the media over the past 10 years, with several participants explicitly stating they now see more positive mental health content than negative. However, some participants felt that the negative content has a significantly stronger impact on the public and all participants expressed the view that there are not enough recovery stories in the media, including examples of successful interventions. Many stressed the importance of recovery stories being told in mainstream news media to balance the negative narrative and provide hope to the audience. Several participants claimed that the media never show recovery from severe episodes of mental illness and give the impression that these cannot be recovered from. It was agreed that the media have a narrow view of recovery, describing it as a state of being recovered, rather than presenting someone as actively in recovery. Participants characterised recovery as nuanced, holistic and personal, and contrary to the media, felt that people can live flourishing lives in the presence of symptoms.

\section{Discussion}

This research set out to explore the views of key informants regarding the representation of mental health by the New Zealand media. From the perspectives of these key informants, the media have a significant role to play in influencing public opinion on mental health. This is congruent with similar research that has found that the media have significant influence over public attitudes towards mental illness (e.g., Anderson, 2003; Klin \& Lemish, 2008; Wilson, Nairn, Coverdale, \& Panapa, 2000) and fictional and non-fictional depictions are mutually reinforcing and cumulative (Nairn, 2007; Stuart, 2006). While there was optimism about the increase in recovery and anti-stigma messages in the media, this was tempered by an understanding of the power of negative media representations. Participants were unanimous in their belief that the media can change public perceptions of mental health and create a more inclusive society. However, participants varied in how optimistic they were concerning media intentions and some made it clear they did not think the current media climate would prioritise de-stigmatisation over sensationalism.

\section{Regarding journalism}

There is ample academic literature analysing the evolution of language in mental health with recent research noting the phasing out of derogatory terms in both the media and in public discourses (Kenez et al., 2015; Romm, 2015). In line with this, interview participants expressed the belief that these terms are becoming less prevalent in media material. The reduction of derogatory language has been accompanied by the introduction of recovery-focused language and an emphasis on health and wellness.

As Beresford (2002) argues, a focus on mental health rather than mental illness helps to reduce the divide between the sick and the healthy, recognising that mental health exists on a continuum and can fluctuate over a lifespan. This was highlighted in the results of the interviews, which found an agreement among participants that language has indeed improved and the media is making more of an effort to emphasise the importance of mental health and holistic wellbeing, as opposed solely to the experience of mental illness. This indicates 
that it is possible to teach journalists how to report on stories detailing an experience of mental distress without re-traumatising others or reproducing stigma. Similar studies suggest that, even in the context of crime and violence, skilled journalists are able to provide an informative and balanced account of an event (Berry \& Whitley, 2016).

As emphasised by interview participants, service-users are the most affected by media representations of mental health, particularly when representations are negative and inaccurate. Negative media has the ability to impact on every facet of a service-user's life; from their identity and self-worth to the places they can live and the supports available. In the interview findings, discussion around identity occurred, with participants commenting on the media's use of diagnostic labels to define an individual by their mental illness. The use of nominalisation in the media creates a dominant identity which undermines the existence of other identities (Aragonès et al., 2014; Murphy et al., 2013). Key informants felt journalists require further education around the impact of language as participants believed that most journalists are not malicious, but naïve, and the language they use which is stigmatising or triggering is unintentional.

\section{Regarding a balanced media}

For media coverage to be balanced, the context in which an event occurs must be given consideration. In the interviews, the broader social and environmental factors that determine mental health were commonly discussed. Participants expressed the belief that mental health is interlinked with other social issues and personal traumas, and emphasised that mental illness does not exist in isolation. However, when the media reports on an incident involving someone with a mental illness, explanation of their past trauma or personal struggles leading up to the incident are typically not given. Moreover, previous research has found the media will often insinuate motives for violent behaviours by being vague in their reports and relying on the public's assumptions about mental illness (Kenez et el., 2015; Ohlsson, 2018).

A desire for the media to consult and liaise with informed sources before publishing a story was stressed by the majority of interview participants. Previous research studies have found promise in interventions which improve reporters' access to information as this provides journalists with a more complete and balanced understanding (Aragonès et al., 2014; Pirkis, Blood, Francis, \& McCallum, 2006; Stuart, 2003; Wahl, 2003). Liaison between the media and mental health professionals, advocates, service-users and their families provides journalists with a range of perspectives, including personal accounts. This allows for accurate and more empathetic mental health stories. As a number of research participants suggested, many service-users who had approached the media in the past felt they were misrepresented. Consequently, serviceusers are somewhat reluctant to speak to the media for fear of negative coverage. The need to prepare individuals to liaise with the media is suggested by Morris (2006) and was also suggested by several participants in this research.

\section{Regarding representation}

De-stigmatisation campaigns are beginning to take effect in Aotearoa New Zealand and are changing the way people view mental distress. It is increasingly recognised that people will experience varying states of mental health throughout their lives, often in response to changing circumstances and environments (Petrillo, Capone, Caso, \& Keyes, 2015; Romm, 2015; Westerhof \& Keyes, 2010). Participants felt that these campaigns are responsible for the reduction in negative attitudes from others and for removing some of the weight of self-stigma (Scambler, 2009) for those experiencing depression. 
Some mental health conditions such as psychoses occur less frequently than depression or anxiety in media stories and are described with a reduced amount of empathy and understanding, as shown by previous research (e.g., Nordt, Rössler, \& Lauber, 2006; Wood, Birtel, Alsawy, Pyle, \& Morrison, 2014). Currently, it seems that the media mention psychosis or schizophrenia only in the event of a tragedy. This gives the impression that these major mental illnesses are a determinant or prerequisite to violence, when the actual perpetration of violence by someone with any major mental illness is relatively rare (Simpson et al., 2004).

Indications that the media can be a powerful vehicle for combatting stigma and dispelling myths has been a recurring theme in comparable research studies (Angermeyer \& Schulze, 2001; Aragonès et al., 2014; Clement et al., 2013; Dietrich, Heider, Matschinger, \& Angermeyer, 2006; Morgan \& Jorm, 2009; Stuart, 2006). Of particular significance are media campaigns involving famous people with lived experience of mental illness, as these have been shown to increase public interest and awareness of mental health issues and reduce beliefs that mental illness is a sign of weakness (Morgan \& Jorm, 2009; Vaughan \& Hansen, 2004; Whitley \& Wang, 2017).

The findings suggest that personal accounts of mental illness humanise the issues and encourage the public to respond with acceptance and understanding rather than fear. It was suggested by interview participants that depression is better represented in the media and efforts have been made to destigmatise and normalise experiences of depression in a way that has not been done for other presentations of mental distress. Other recent research, by Neto et al. (2017) and Rhydderch et al. (2016), supports this assertion, which provides evidence to suggest that further intervention is required to remove the stigma associated with major mental illness, especially where there may be a perception of risk or violence.

\section{Regarding hope}

The recovery model promotes the idea that people with mental illness can improve, manage symptoms, and live meaningful lives (Charles \& Bentley, 2016; Lloyd, King, \& Moore, 2010), and thus contradicts the belief that mental illness is something that needs to be "cured" or something that cannot be recovered from. Recovery stories provide hope and guidance for people experiencing mental distress and help to disprove stigmatising myths and educate the public (Wisdom, Bruce, Auzeen Saedi, Weis, \& Green, 2008). The narratives of interview participants reflected this view, suggesting that personal accounts of recovery have powerful effects on the general public and on those currently experiencing distress. Furthermore, the negative impact of suicide stories can be ameliorated when stories model healthy ways of managing distress and show people who have survived mental illness rather than those who have attempted or completed suicide (Morgan \& Jorm, 2009). By doing this, the media are able to foster hope and motivate vulnerable people to seek new ways of coping, instead of presenting suicide as a solution (Niederkrotenthaler et al., 2010; Sisask \& Värnik, 2012).

Despite systemic barriers, mental health professionals have many successes in their day-to-day practice that are seldom mentioned in the media. Indeed, the participants in this research described a number of privacy restrictions that prevent mental health professionals from disclosing information about the work they do, including successful interventions with clients. The idea that mental health professionals are unable to voice their experiences was frequently expressed by participants in this study, resulting in the media portraying an incomplete picture of how mental health services are operating.

The findings indicate that current media portrayals create challenges for mental health professionals in acquiring the trust of service-users. This leads to a situation where 
mental health professionals are having to spend longer building relationships with their clients before they are able to aid in recovery (Klin \& Lemish, 2008). Although media coverage of failing services may raise awareness of the issues and encourage government intervention, portraying a system in crisis discourages help-seeking and leads people to adopt a hopeless orientation. Positive representations of services may potentially have the opposite effect (Stuart, 2003) but were scarcely present in these findings. This suggests a situation where people in distress lack confidence in the capability of the mental health services to get them well. These findings are in line with similar research that has found that distrust of services can prevent help-seeking and lead to the avoidance of certain treatments (Ohlsson, 2018; Stuart, 2006).

\section{Recommendations}

The results of this research suggest that the representation of mental health in the media has changed, and predominately for the better. However, areas remain where improvements can still be made, and intervention is warranted. This section presents some of the recommendations arising out of this research.

1. Adequately train journalists: $A$ central recommendations which came out of this research is to train journalists to report on mental health stories in a way that captures the essence of the story while remaining sensitive. We acknowledge the existence of guidelines for media reporting, such as the Mental Health Foundation guidelines (MHF, 2008) and the media Roundtable resource developed for the Ministerial Committee on Suicide Prevention (Ministry of Health, 2011): it is in the adherence to these guidelines where we feel there is room for improvement. While information is available it may not always be effectively utilised (MHF online).
Participants suggested implementing policies to ensure the media is consistent and accountable for the messages they convey. Policy changes could include consideration of mandatory consultation with serviceusers before releasing a story and a requirement to provide background information. We believe providing resources on the language to use and the impacts of negative reporting will encourage journalists to change the way they report on mental health stories. This would provide necessary guidance for journalists and would enable an authentic representation of mental health without re-traumatising the audience or reproducing stigma.

\section{Media liaison training for mental} health professionals and serviceusers: In line with the research of Wahl (2003), media training for mental health professionals and service-users was also recommended in this study. Media liaison enables professionals to use their platform to educate the public and promote positive messages. For service-users, training provides them with the confidence to work with the media and allows them to share their journey in a way that can induce hope in others.

3. Include recovery stories from a broader range of mental illnesses: Unlike experiences of mental illness such as anxiety and depression, disorders such as schizophrenia are rarely represented positively in the media. For mental illnesses to be understood and accepted rather than feared, people with lived experience of these conditions need to have their experiences shared in the media. By exposing the realities of living with these conditions, particularly by sharing stories of recovery, the media can normalise experiences of extreme 
distress and disprove harmful myths about mental illness.

\section{Publish successful intervention} stories: The results of this research suggest that recovery stories are becoming more prominent in the media; however, what participants felt was missing were illustrations of successful interventions. Successful interventions are not often discussed in the media and, instead, the failings of mental health services are emphasised. Services are being poorly represented by the media and at the same time people are being urged to reach out to these services. Without examples of successful interventions to provide balance to the negative stories, people are understandably dubious about the capabilities of mental health services and are unlikely to reach out. Stories of successful interventions have the potential to not only encourage helpseeking but can change the public's perception of services users and gain the public's support for increasing the funding of effective services.

\section{Conclusion}

This study found indications of a shift in the media's portrayal of certain diagnoses and suggests that the media are now attempting to change public attitudes by engaging in responsible reporting and opening conversations. Another article addressing the content analysis aspect of this research will explore this finding further, by examining a sample of news media articles on depression and suicide.

Unfortunately, the representation of other areas of mental health has not yet undergone a similar change. For this to occur, the barriers for journalists identified by participants will each need to be addressed. Many of these will call for service-user input, for example accurately representing a successful intervention or the reality of living with a major mental illness will require liaison with individuals with these experiences (Rhydderch et al., 2016). Further training is needed for the media and serviceusers to build collaborative relationships and equip them with the skills to retell mental health stories in ways that induce hope and cultivate acceptance.

This research has examined how mental health in New Zealand is currently being represented by the news media, exploring the perspectives of key informants on what the potential impacts of this representation might be. One of the limitations of the research is its small and predetermined sample size. Due to the recruitment method and the different roles of participants, the findings cannot be said to be representative of any wider population. This method was intentional and in line with the aims of the study, as it allowed for different voices on the topic, and potentially contrasting perspectives, to emerge within the scope of this study.

Overall, this research points to a progressive and responsive news media that is beginning to use its influence to create awareness and engage the public in an informative dialogue on mental health issues. While there are still flaws in media representation, positive steps have been taken and we are now seeing a resulting change in society on the value given to individuals with lived experience of mental illness.

Accepted 19 August 2020

Published 15 December 2020

\section{References}

Anderson, M. (2003). "One flew over the psychiatric unit": Mental illness and the media. Journal of Psychiatric and Mental Health Nursing, 10(3), 297-306.

Angermeyer, M. C., \& Schulze, B. (2001). Reinforcing stereotypes: How the focus on forensic cases in news reporting may influence public attitudes towards the mentally ill. International Journal of Law and Psychiatry, 24(4-5), 469-486.

Aragonès, E., López-Muntaner, J., Ceruelo, S., \& Basora, J. (2014). Reinforcing stigmatization: Coverage of mental illness in Spanish newspapers. Journal of Health Communication, 19(11), 1248-1258. 
Beresford, P. (2002). Thinking about "mental health": Towards a social model. Journal of Mental Health, 11(6), $581-584$

Beresford, P. (2019). 'Mad', mad studies and advancing inclusive resistance. Disability \& Society, 1-6. doi:10.108 0/09687599.2019.1692168

Berry, S., \& Whitley, R. (2016). Stigmatizing representations: Criminality, violence, and mental illness in Canadian mainstream media In R. Smith Fullerton \& C. Richardson (Eds.), Covering Canadian crimes: What journalists should know and the public should question (pp. 346-365). University of Toronto Press.

Borgatti, S. (2014). Introduction to grounded theory. Retrieved from http://www.analytictech.com/mb870/ introtogt.htm

Bryman, A. (2012). Social research methods (5th ed.). Oxford University Press.

Charles, J. L., \& Bentley, K. J. (2016). Stigma as an organizing framework for understanding the early history of community mental health and psychiatric social work. Social Work in Mental Health, 14(2), 149-173.

Clement, S., Lassman, F., Barley, E., Evans-Lacko, S., Williams, P., Yamaguchi, S., . . . Thornicroft, G. (2013). Mass media interventions for reducing mental healthrelated stigma. The Cochrane Database of Systematic Reviews, 7, CD009453. doi:10.1002/14651858. CD009453.pub2

Dietrich, S., Heider, D., Matschinger, H., \& Angermeyer, M. (2006). Influence of newspaper reporting on adolescents' attitudes toward people with mental illness. Social Psychiatry and Psychiatric Epidemiology, 41(4), 318-322. doi:10.1007/s00127-005-0026-y

Drake, R. E., \& Whitley, R. (2014). Recovery and severe mental illness: Description and analysis. The Canadian Journal of Psychiatry, 59(5), 236-242.

Gill, P., Stewart, K., Treasure, E., \& Chadwick, B. (2008) Methods of data collection in qualitative research: Interviews and focus groups. British Dental Journal, 204(6), 291-295.

Gubrium, J. F., Holstein, J. A., Marvasti, A. B., \& McKinney, K. D. (2012). The SAGE handbook of interview research: The complexity of the craft (2nd ed.). Sage.

Hall, S. (2001). Foucault: Power, knowledge and discourse. In M. Wetherell, S. Taylor, \& S. J. Yates (Eds.), Discourse theory and practice: A reader (pp. 72-81). Sage.

Kenez, S., O'Halloran, P., \& Liamputtong, P. (2015). The portrayal of mental health in Australian daily newspapers. Australian and New Zealand Journal of Public Health, 39(6), 513-517.

Klin, A., \& Lemish, D. (2008). Mental disorders stigma in the media: Review of studies on production, content, and influences. Journal of Health Communication, 13(5), 434-449.

Lloyd, C., King, R., \& Moore, L. (2010). Subjective and objective indicators of recovery in severe mental illness: A cross-sectional study. International Journal of Social Psychiatry, 56(3), 220-229.

Marshall, C., \& Rossman, G. B. (2014). Designing qualitative research (6th ed.). Sage.
Mental Health Foundation of New Zealand. (2014). Mental health foundation: Quick facts and stats 2014. Retrieved from https://www.mentalhealth.org.nz/assets/Uploads/ MHF-Quick-facts-and-stats-FINAL.pdf

Mental Health Foundation of New Zealand. (2018). Mental Health Foundation media guidelines: Portrayal of people living with mental illness and mental health issues in Aotearoa. Retrieved from https://www.mentalhealth.org nz/get-help/media-guidelines/

Ministry of Health. (2011). Reporting suicide: A resource for the media. Media Roundtable/Author.

Ministry of Health and Health Promotion Agency. (2014). Like Minds, Like Mine National Plan 2014-2019: Programme to increase social inclusion and reduce stigma and discrimination for people with experience of mental illness. Ministry of Health.

Morgan, A. J., \& Jorm, A. F. (2009). Recall of news stories about mental illness by Australian youth: Associations with help seeking attitudes and stigma. Australian and New Zealand Journal of Psychiatry, 43(9), 866-872. doi:10.1080/00048670903107567

Morris, G. (2006). Mental health issues and the media: An introduction for health professionals. Routledge.

Murphy, N. A., Fatoye, F., \& Wibberley, C. (2013). The changing face of newspaper representations of the mentally ill. Journal of Mental Health, 22(3), 271-282.

Nairn, R., Coverdale, J., \& Claasen, D. (2001). From source material to news story in New Zealand print media: A prospective study of the stigmatizing processes in depicting mental illness. Australian and New Zealand Journal of Psychiatry, 35(5), 654-659.

Nairn, R. G. (2007). Media portrayals of mental illness, or is it madness? A review. Australian Psychologist, 42(2), 138-146.

Neto, D. D., Figueiras, M. J., Campos, S., \& Tavares, P. (2017). Impact of economic crisis on the social representation of mental health: Analysis of a decade of newspaper coverage. International Journal of Social Psychiatry, 63(8), 736-743.

Niederkrotenthaler, T., Voracek, M., Herberth, A., Till, B., Strauss, M., Etzersdorfer, E., . . Sonneck, G. (2010). Role of media reports in completed and prevented suicide: Werther v. Papageno effects. The British Journal of Psychiatry: The Journal of Mental Science, 197(3), 234-243. doi:10.1192/bjp.bp.109.074633

Nordt, C., Rössler, W., \& Lauber, C. (2006). Attitudes of mental health professionals toward people with schizophrenia and major depression. Schizophrenia Bulletin, 32(4), 709-714.

Ohlsson, R. (2018). Public discourse on mental health and psychiatry: Representations in Swedish newspapers. Health, 22(3), 298-314.

Oliver, N. (2019). Mental health and the media in Aotearoa New Zealand (Unpublished master's thesis), University of Auckland, NZ.

Peterson, D., Barnes, A. \& Duncan, C. (2008). Fighting shadows: Self-stigma and mental illness (Whawhai Atu te Whakamā Hihira). Mental Health Foundation of New Zealand

Petrillo, G., Capone, V., Caso, D., \& Keyes, C. L. (2015). The mental health continuum-Short form (MHC-SF) as a measure of well-being in the Italian context. Social Indicators Research, 121(1), 291-312. 
Pirkis, J., Blood, R. W., Francis, C., \& McCallum, K. (2006). On-screen portrayals of mental illness: Extent, nature, and impacts. Journal of Health Communication, 11(5), 523-541.

Rhydderch, D., Krooupa, A., Shefer, G., Goulden, R. Williams, P., Thornicroft, A., . . . Henderson, C. (2016) Changes in newspaper coverage of mental illness from 2008 to 2014 in England. Acta Psychiatrica Scandinavica, 134, 45-52.

Romm, C. (2015, October 28). The changing vocabulary of mental illness: Why your doctor no longer says you're "going mad." The Atlantic. Retrieved from https://www. theatlantic.com/health/archive/2015/10/mental-healthwords $/ 412630$

Sampogna, G., Bakolis, I., Evans-Lacko, S., Robinson, E., Thornicroft, G., \& Henderson, C. (2017). The impact of social marketing campaigns on reducing mental health stigma: Results from the 2009-2014 Time to Change programme. European Psychiatry, 40, 116-122. doi. org/10.1016/j.eurpsy.2016.08.008

Scambler, G. (2009). Health-related stigma. Sociology of Health \& IIIness, 31(3), 441-455. doi:10.1111/j.1467-9566.2009. 01161.x

Schrader, S., Jones, N., \& Shattell, M. (2013). Mad pride: Reflections on sociopolitical identity and mental diversity in the context of culturally competent psychiatric care. Issues in Mental Health Nursing, 34(1), 62-64. doi:10.31 09/01612840.2012.740769

Simpson, A. I., Mckenna, B., Moskowitz, A., Skipworth, J., \& Barry-Walsh, J. (2004). Homicide and mental illness in New Zealand, 1970-2000. The British Journal of Psychiatry, 185(5), 394-398.

Sisask, M., \& Värnik, A. (2012). Media roles in suicide prevention: A systematic review. International Journal of Environmental Research and Public Health, 9(1), 123-138. doi:10.3390/ijerph9010123

Steward, W., Herek, G., Ramakrishna, J., Bharat, S., Chandy, S., Wrubel, J., \& Ekstrand, M. (2008) HIVrelated stigma: Adapting a theoretical framework for use in India. Social Science and Medicine, 67(8), 1225-1235.

Stuart, H. (2003). Stigma and the daily news: Evolution of a newspaper intervention. Canadian Journal of Psychiatry, 48(10), 651-656. https://doi. org/10.1177/070674370304801002

Stuart, H. (2006). Media portrayal of mental illness and its treatments. CNS Drugs, 20(2), 99-106.

Thornicroft, A., Goulden, R., Shefer, G., Rhydderch, D., Rose, D., Williams, P., ... Henderson, C. (2013). Newspaper coverage of mental illness in England 20082011. The British Journal of Psychiatry, 202(s55), s64s69. doi:10.1192/bjp.bp.112.112920

Thornicroft, C., Wyllie, A., Thornicroft, G., \& Mehta, N. (2014). Impact of the "like minds, like mine" anti-stigma and discrimination campaign in New Zealand on anticipated and experienced discrimination. The Australian and New Zealand Journal of Psychiatry, 48(4), 360-370. doi:10.1177/0004867413512687

Vaughan, G., \& Hansen, C. (2004). Like minds, like mine: A New Zealand project to counter the stigma and discrimination associated with mental illness. Australasian Psychiatry, 12(2), 113-117. doi:10.1111/ j.1039-8562.2004.02083.x
Wahl, O. F. (2003). News media portrayal of mental illness: Implications for public policy. American Behavioral Scientist, 46(12), 1594-1600.

Wahl, O. F., Wood, A., \& Richards, R. (2002). Newspaper coverage of mental illness: Is it changing? Psychiatric Rehabilitation Skills, 6(1), 9-31.

Westerhof, G. J., \& Keyes, C. L. (2010). Mental illness and mental health: The two continua model across the lifespan. Journal of Adult Development, 17(2), 110-119.

Whitley, R., \& Wang, J. (2017). Good news? A longitudinal analysis of newspaper portrayals of mental illness in Canada 2005 to 2015. The Canadian Journal of Psychiatry, 62(4), 278-285.

Wilson, C., Nairn, R., Coverdale, J., \& Panapa, A. (1999). Constructing mental illness as dangerous: A pilot study. Australian and New Zealand Journal of Psychiatry, 33(2), 240-247.

Wilson, C., Nairn, R., Coverdale, J., \& Panapa, A. (2000). How mental illness is portrayed in children's television: A prospective study. The British Journal of Psychiatry, 176(5), 440-443.

Wisdom, J. P., Bruce, K., Auzeen Saedi, G., Weis, T., \& Green, C. A. (2008). "Stealing me from myself": Identity and recovery in personal accounts of mental illness. Australian \& New Zealand Journal of Psychiatry, 42(6), 489-495.

Wood, L., Birtel, M., Alsawy, S., Pyle, M., \& Morrison, A. (2014). Public perceptions of stigma towards people with schizophrenia, depression, and anxiety. Psychiatry Research, 220(1-2), 604-608. 